\title{
Entropy-driven mechanisms between disulfide bond formation protein A (DsbA) and B (DsbB) in Escherichia coli
}

\author{
Kenjiro Yazawa ${ }^{1,3}$ and Hiroyuki Furusawa*,2,3 \\ ${ }^{1}$ Division of Biological and Medical Fibers, Interdisciplinary Cluster for Cutting Edge \\ Research, Institute for Fiber Engineering, Shinshu University, 3-15-1, Tokida, Ueda City, \\ Nagano 386-8567, Japan. \\ ${ }^{2}$ Innovative Flex Course for Frontier Organic Material Systems (iFront), Graduate School of \\ Science and Engineering, Yamagata University, 4-3-16 Jonan, Yonezawa, Yamagata 992- \\ 8510, Japan. \\ ${ }^{3}$ Department of Biomolecular Engineering, Tokyo Institute of Technology, 4259 Nagatsuta, \\ Midori-ku, Yokohama, Kanagawa 226-8501, Japan
}

\section{Corresponding Author}

*E-mail: hfurusaw@yz.yamagata-u.ac.jp. Phone/Fax: +81-238-26-3841.

\section{Table of contents}

Figure S1. Effect of UQ on the complex formation between DsbA(C33A $)_{\mathrm{SH}}$ and $\mathrm{DsbB}_{\mathrm{S}-\mathrm{S}, \mathrm{S}-\mathrm{S}}$ evaluated by QCM experiments at $\mathrm{pH}$ 6.0.

Figure S2. Effect of UQ on the complex formation between DsbA(C33A $)_{\mathrm{SH}}$ and $\mathrm{DsbB}_{\mathrm{S}-\mathrm{S}, \mathrm{S}-\mathrm{S}}$ evaluated by QCM experiments at $\mathrm{pH}$ 7.5.

Figure S3. Effect of UQ on the complex formation between DsbA(C33A $)_{\mathrm{SH}}$ and $\mathrm{DsbB}_{\mathrm{S}-\mathrm{S}, \mathrm{S}-\mathrm{S}}$ evaluated by QCM experiments at $\mathrm{pH}$ 9.0.

Figure S4. Confirmation of oxidation of the DsbB-UQ complex by the addition of exogenous UQ (UQ1) using QCM measurement.

Figure S5. Schematic illustration of $\mathrm{p} K_{\mathrm{a}}$ determination of cysteine residues in DsbA and DsbB using SDS-PAGE mobility shift assay.

Figure S6. Effect of $\mathrm{pH}$ on the amount of native DsbA modified with malPEG over a wide $\mathrm{pH}$ range monitored by SDS-PAGE analyses.

Figure S7. Determination of $\mathrm{p} K_{\mathrm{a}}$ of Cys44 in DsbB using SDS-PAGE mobility shift assay.

Figure S8. Determination of $\mathrm{p} K_{\mathrm{a}}$ of Cys130 in DsbB using SDS-PAGE mobility shift assay. 
(a)
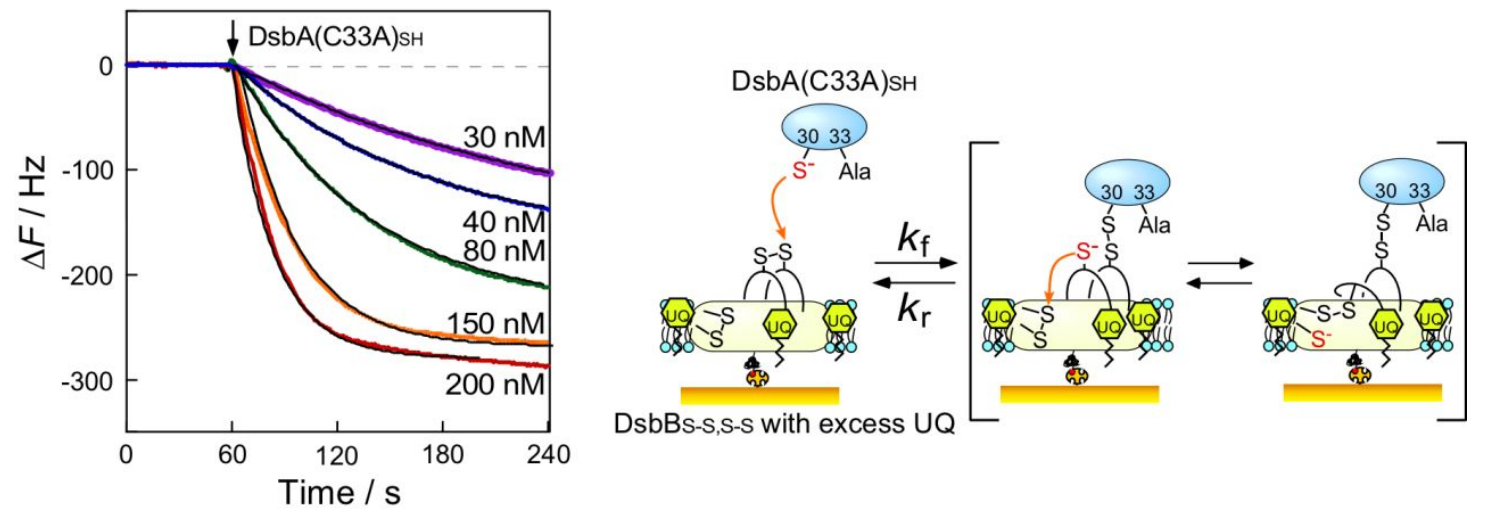

(b)
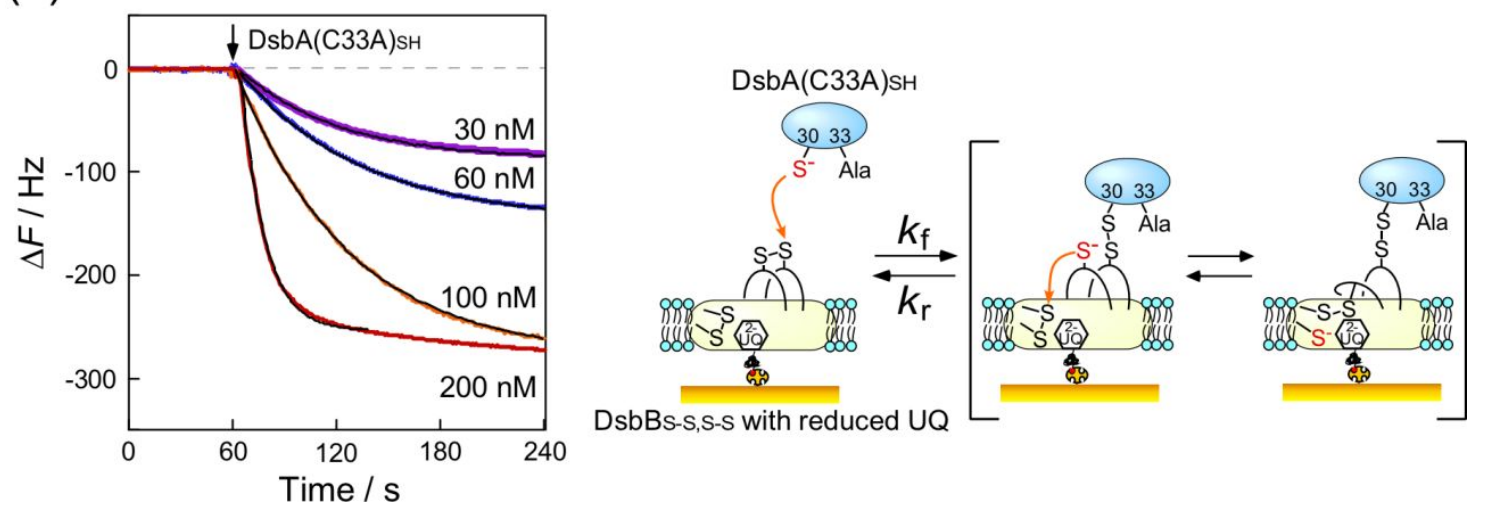

Figure S1. Effect of UQ on time courses of frequency changes $(\Delta F)$ showing the complex formation between $\operatorname{DsbA}(\mathrm{C} 33 \mathrm{~A})_{\mathrm{SH}}$ and $\mathrm{DsbB}_{\mathrm{S}-\mathrm{S}, \mathrm{S}-\mathrm{S}}$ in the presence of (a) excess UQ and (b) $\mathrm{UQ}^{2-}$ in QCM experiments at $\mathrm{pH}$ 6.0. The experiments were carried out under the following conditions: $50 \mathrm{mM}$ citrate, $\mathrm{pH} 6.0$, and $100 \mathrm{mM} \mathrm{NaCl}$ at $25{ }^{\circ} \mathrm{C}$. The final concentrations of $\operatorname{DsbA}(\mathrm{C} 33 \mathrm{~A})_{\mathrm{SH}}$ in $500 \mu \mathrm{L}$ of a QCM cell were shown in the chart. The immobilization amount of DsbB was $16 \mathrm{pmol} / \mathrm{cm}^{2}$ on the QCM plate. Experimental curves are shown in colored lines and fitted curves are indicated as black smooth lines. 
(a)
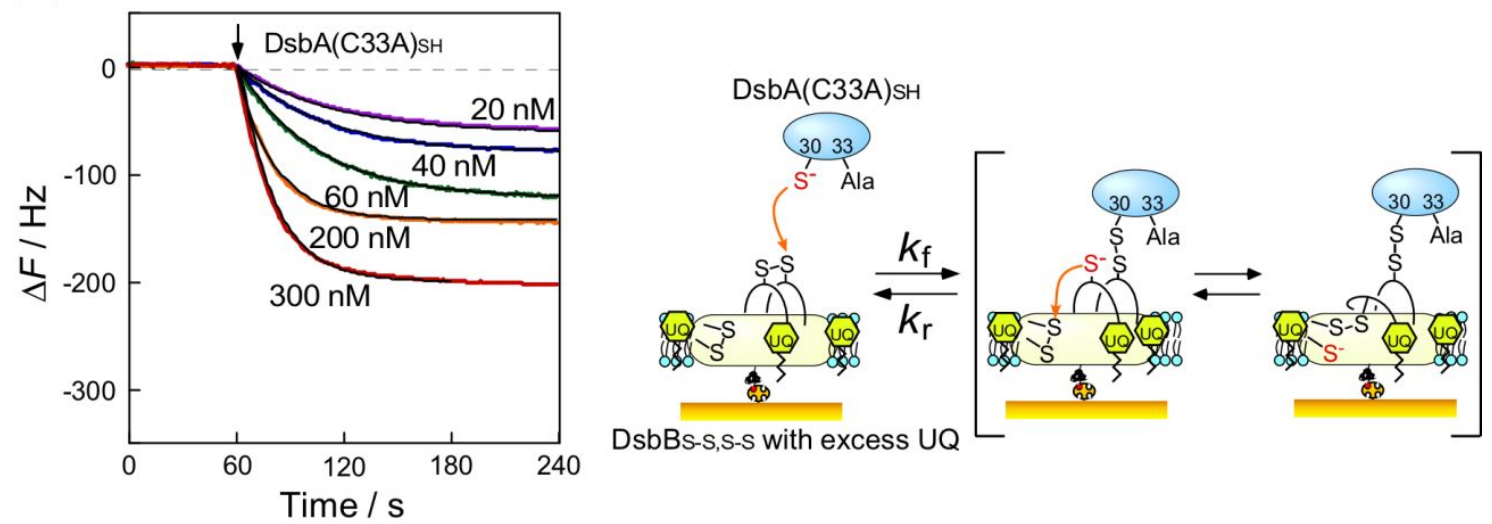

(b)
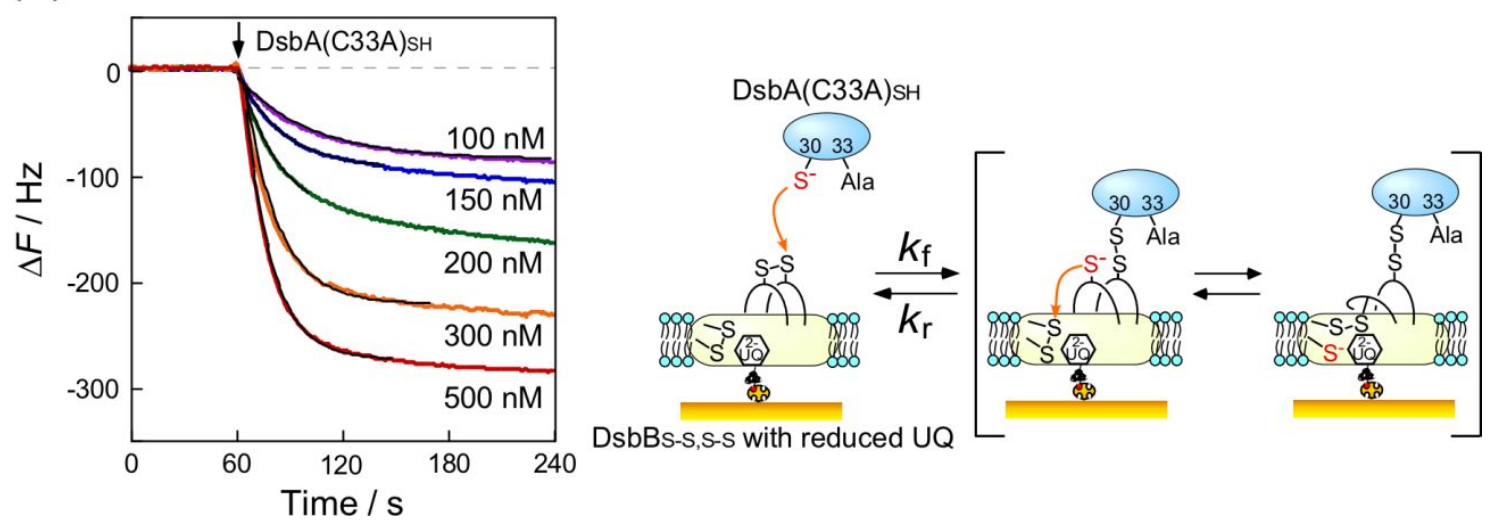

Figure S2. Effect of UQ on time courses of frequency changes $(\Delta F)$ showing the complex formation between $\operatorname{DsbA}(\mathrm{C} 33 \mathrm{~A})_{\mathrm{SH}}$ and $\mathrm{DsbB}_{\mathrm{S}-\mathrm{S}, \mathrm{S}-\mathrm{S}}$ in the presence of (a) excess UQ and (b) $\mathrm{UQ}^{2-}$ in QCM experiments at $\mathrm{pH}$ 7.5. The experiments were carried out under the following conditions: $50 \mathrm{mM}$ HEPES-NaOH, $\mathrm{pH} 7.5$, and $100 \mathrm{mM} \mathrm{NaCl}$ at $25{ }^{\circ} \mathrm{C}$. The final concentrations of $\operatorname{DsbA}(\mathrm{C} 33 \mathrm{~A})_{\mathrm{SH}}$ in $500 \mu \mathrm{L}$ of a $\mathrm{QCM}$ cell were shown in the chart. The immobilization amount of DsbB was $16 \mathrm{pmol} / \mathrm{cm}^{2}$ on the QCM plate. Experimental curves are shown in colored lines and fitted curves are indicated as black smooth lines. 
(a)
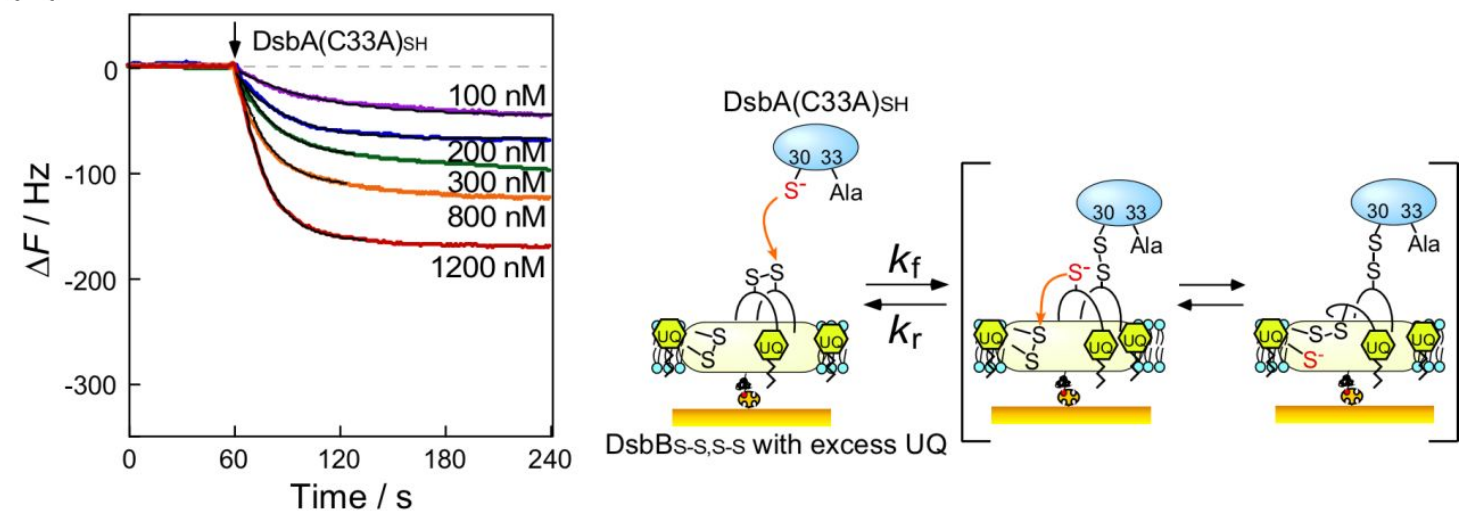

(b)
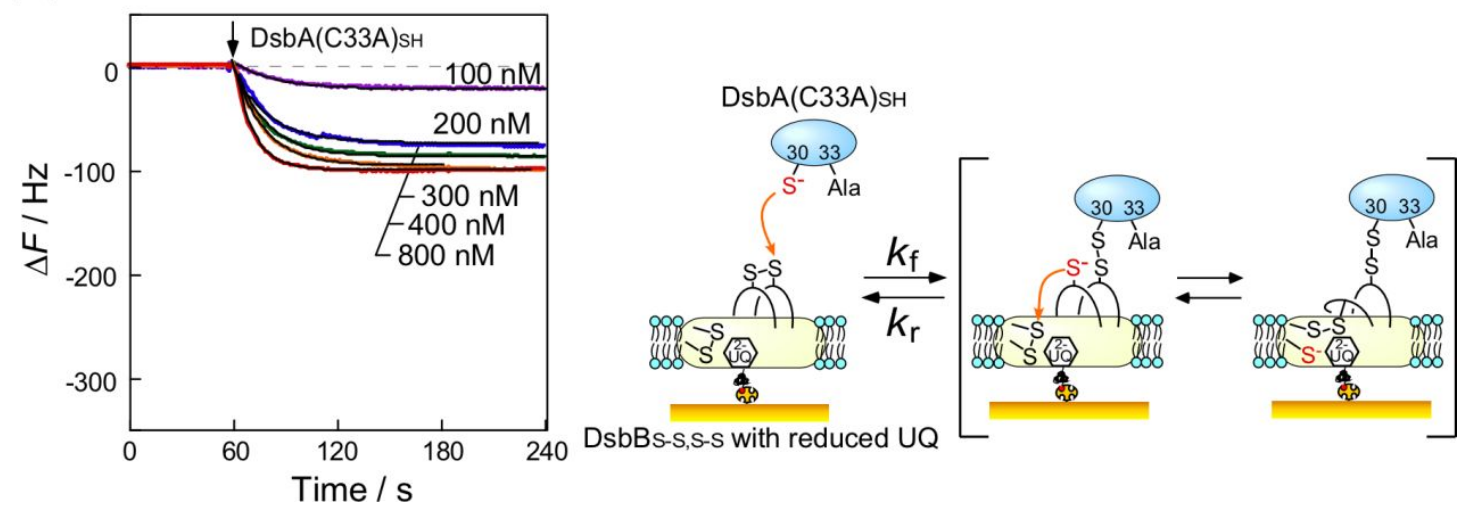

Figure S3. Effect of UQ on time courses of frequency changes $(\Delta F)$ showing the complex formation between $\operatorname{DsbA}(\mathrm{C} 33 \mathrm{~A})_{\mathrm{SH}}$ and $\mathrm{DsbB}_{\mathrm{S}-\mathrm{S}, \mathrm{S}-\mathrm{S}}$ in the presence of (a) excess UQ and (b) $\mathrm{UQ}^{2-}$ in QCM experiments at $\mathrm{pH}$ 9.0. The experiments were carried out under the following conditions: $50 \mathrm{mM}$ Tris- $\mathrm{HCl}, \mathrm{pH} 9.0$, and $100 \mathrm{mM} \mathrm{NaCl}$ at $25^{\circ} \mathrm{C}$. The final concentrations of $\mathrm{DsbA}(\mathrm{C} 33 \mathrm{~A})_{\mathrm{SH}}$ in $500 \mu \mathrm{L}$ of a QCM cell were shown in the chart. The immobilization amount of DsbB was $16 \mathrm{pmol} / \mathrm{cm}^{2}$ on the QCM plate. Experimental curves are shown in colored lines and fitted curves are indicated as black smooth lines. 
(a)
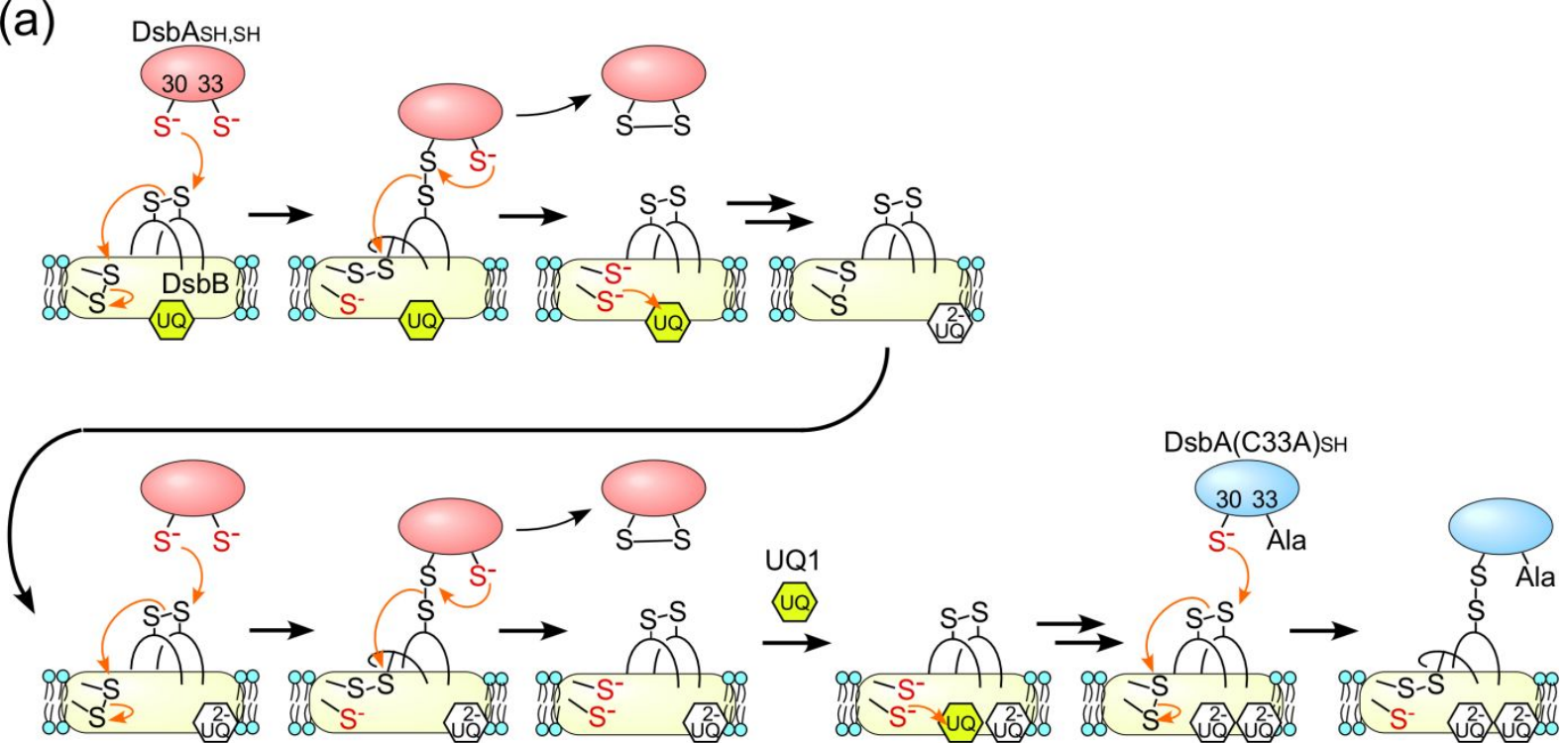

(b)

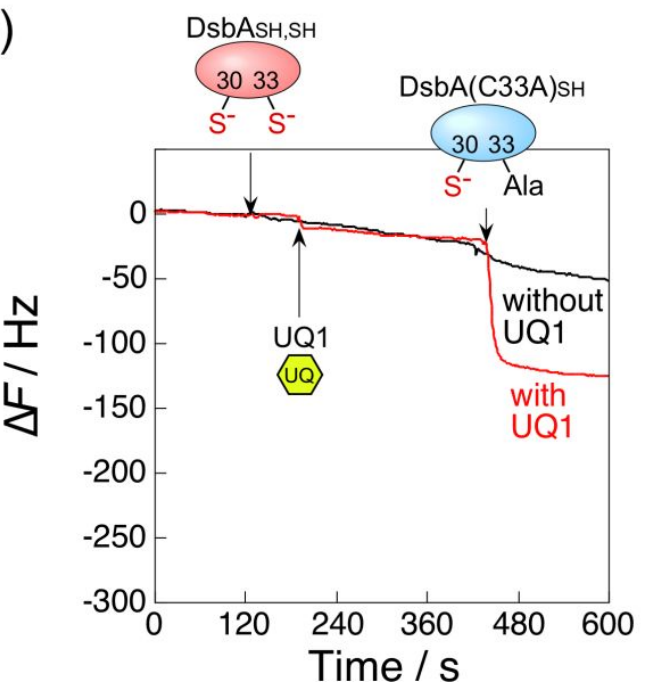

Figure S4. Confirmation of oxidation of the DsbB-UQ complex by the addition of exogenous UQ (UQ1) using QCM measurement at $\mathrm{pH}$ 7.5: (a) schematic illustration of the sequential addition of DsbA and UQ1 to DsbB-immobilized QCM substrate; (b) time courses of the frequency changes $(\Delta F)$ when the sequential addition of $\mathrm{DsbA}_{\mathrm{SH}, \mathrm{SH}}, \mathrm{UQ}$, and $\mathrm{DsbA}(\mathrm{C} 33 \mathrm{~A})_{\mathrm{SH}}$ was performed in the QCM measurement. The experimental condition: $50 \mathrm{mM}$ HEPES-NaOH, $\mathrm{pH} 7.5,100 \mathrm{mM} \mathrm{NaCl}$ at $25^{\circ} \mathrm{C},[\mathrm{DsbA}]=400 \mathrm{nM}$ and [UQ1] $=2,500 \mathrm{nM}$ in $500 \mu \mathrm{L}$, and $[\mathrm{DsbB}]=16 \mathrm{pmol} / \mathrm{cm}^{2}$ on the $\mathrm{QCM}$ plate. 
(a)

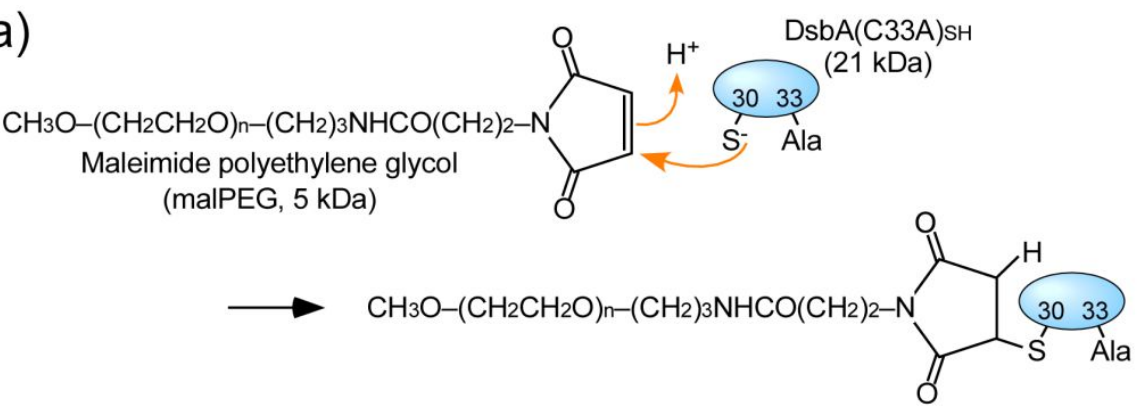

(b)

$$
\zeta=\text { malPEG }
$$
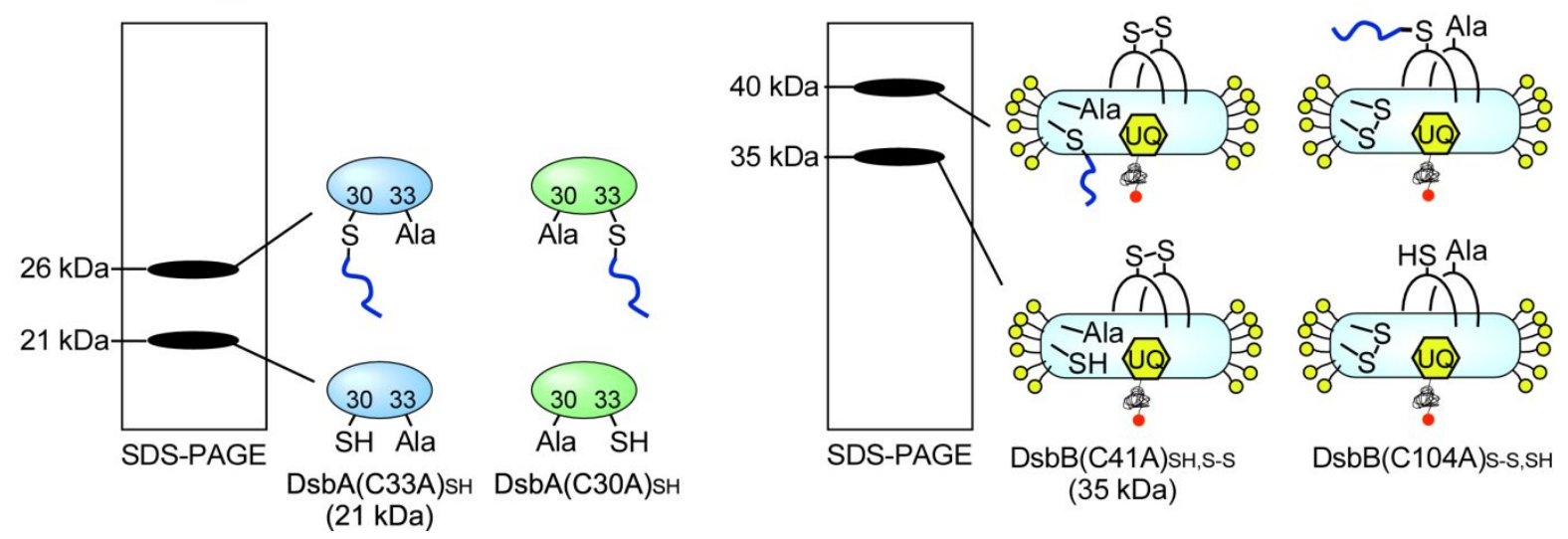

Figure S5. Schematic illustrations of SDS-PAGE mobility shift assay to determine $\mathrm{p} K_{\mathrm{a}}$ of cysteine residues in DsbA and DsbB: (a) modification of a thiolate anion of Cys30 in $\operatorname{DsbA}(\mathrm{C} 33 \mathrm{~A})_{\mathrm{SH}}$ with polyethylene glycol containing maleimide moiety (malPEG) and (b) the band shift after the modification of cysteine residues in DsbA and DsbB with malPEG. 


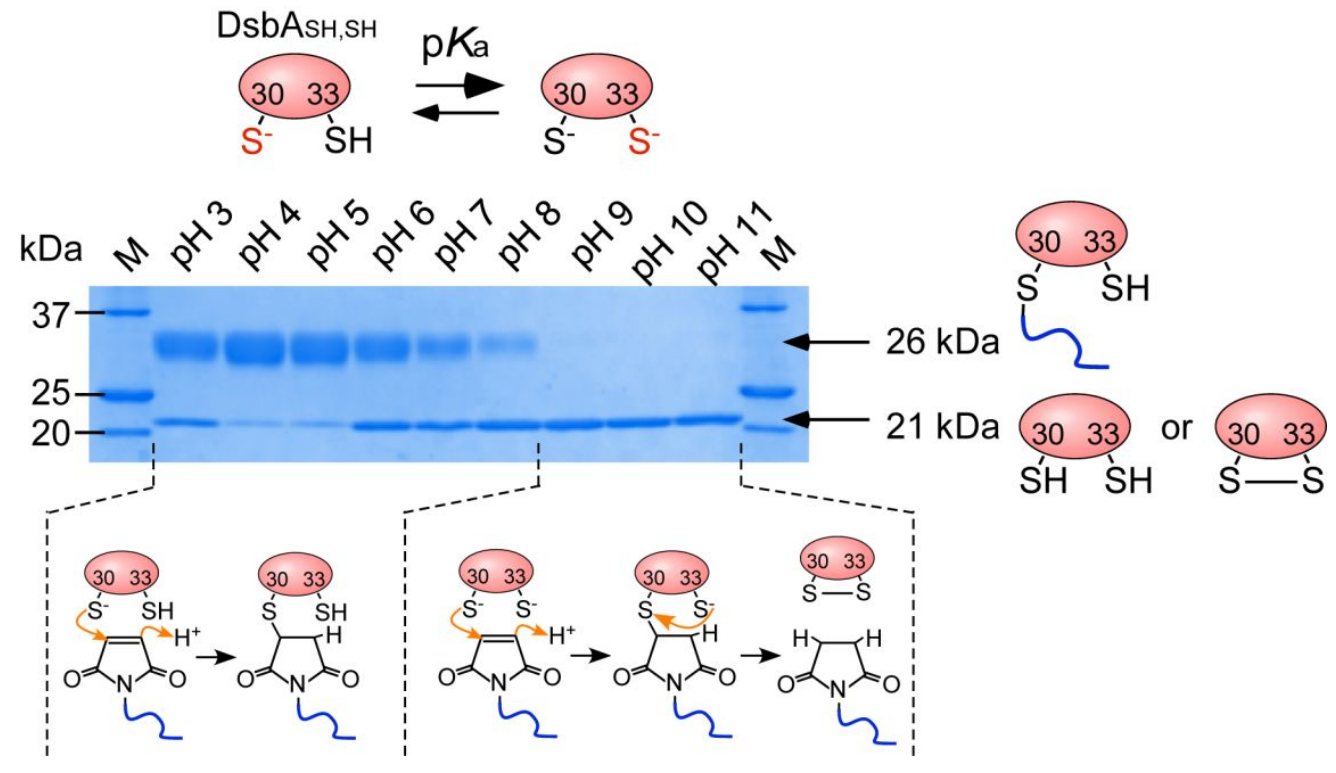

Figure S6. Effect of $\mathrm{pH}$ on the amount of native $\mathrm{DsbA}_{\mathrm{SH}, \mathrm{SH}}(21 \mathrm{kDa})$ modified with maleimidepolyethylene glycol (malPEG, $5 \mathrm{kDa}$ ) over a $\mathrm{pH}$ range from 3 to 11 monitored by SDS-PAGE analyses. 
(a)
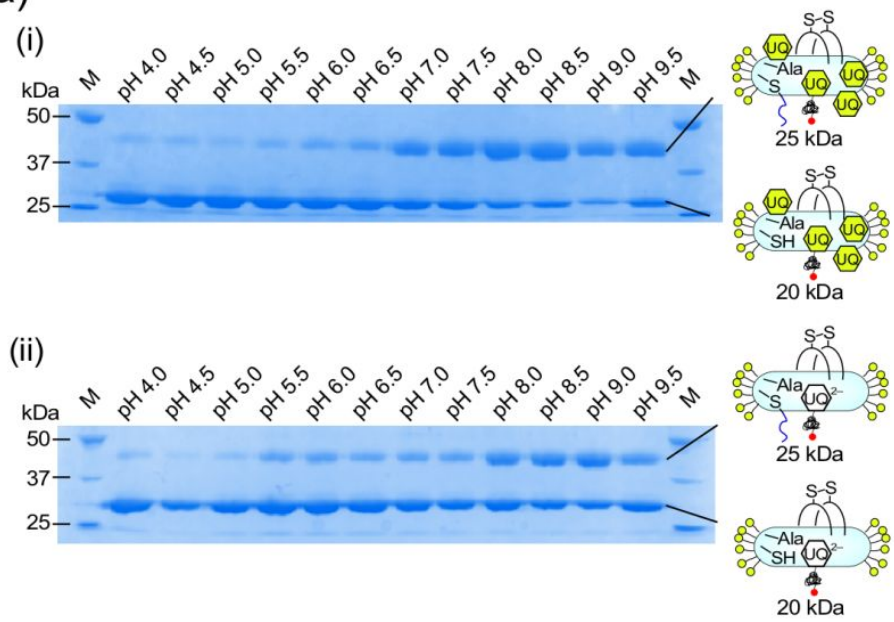

(b)
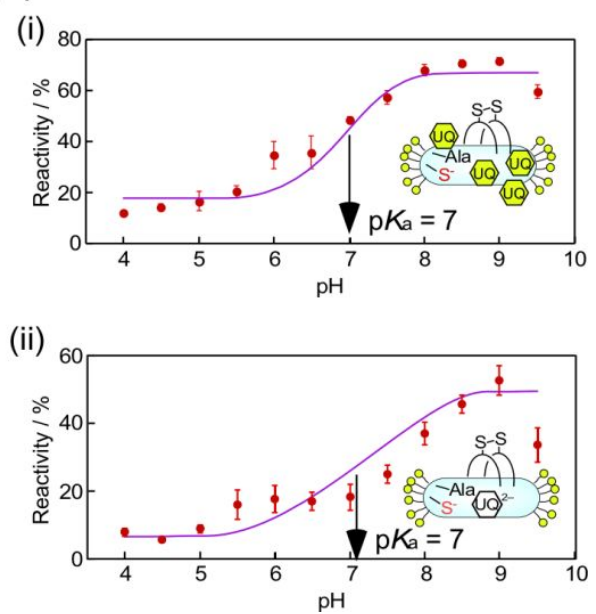

Figure S7. Effect of UQ on the $\mathrm{p} K_{\mathrm{a}}$ of Cys44 in DsbB using malPEG by SDS-PAGE analyses. (a) Effect of $\mathrm{pH}$ on the amount of $\mathrm{DsbB}(\mathrm{C} 41 \mathrm{~A})_{\mathrm{SH}, \mathrm{S}-\mathrm{S}}$ modified with malPEG in the presence of (i) excess UQ and (ii) $\mathrm{UQ}^{2-}$ over a $\mathrm{pH}$ range from 4.0 to 9.5. (b) Effect of $\mathrm{pH}$ on the reactivity of Cys44 with malPEG in the presence of (i) excess UQ and (ii) UQ2- 
(a)

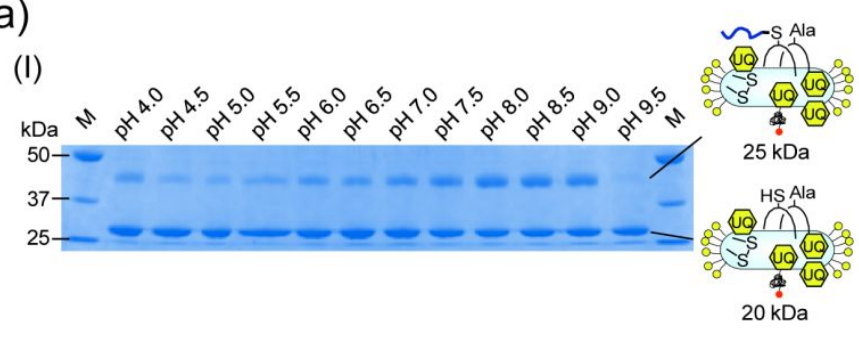

(ii)

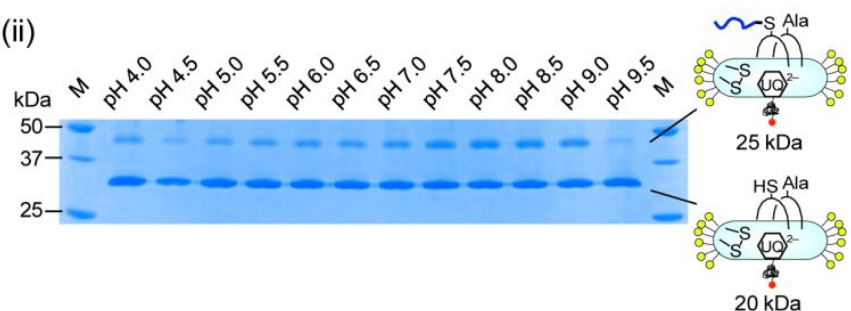

(b)

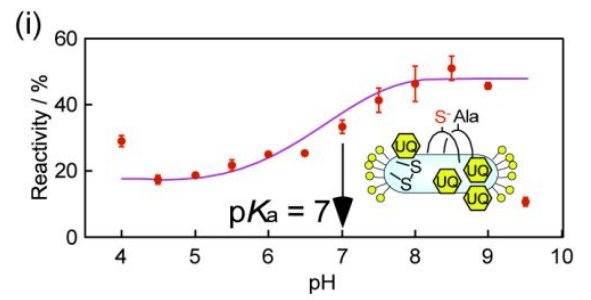

(ii)

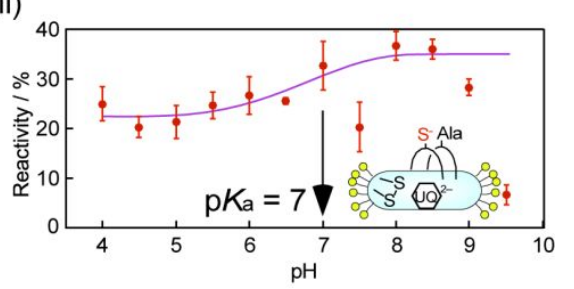

Figure S8. Effect of UQ on the $\mathrm{p} K_{\mathrm{a}}$ of Cys 130 in DsbB using malPEG by SDS-PAGE analyses. (a) Effect of $\mathrm{pH}$ on the amount of $\mathrm{DsbB}(\mathrm{C} 104 \mathrm{~A})_{\mathrm{S}-\mathrm{S}, \mathrm{SH}}$ modified with malPEG in the presence of (i) excess UQ and (ii) $\mathrm{UQ}^{2-}$ over a $\mathrm{pH}$ range from 4.0 to 9.5. (b) Effect of $\mathrm{pH}$ on the reactivity of Cys130 with malPEG in the presence of (i) excess UQ and (ii) $\mathrm{UQ}^{2-}$. 